\title{
sciendo
}

\section{Physical and Physiological Response to Different Modes of Repeated Sprint Exercises in Basketball Players}

\author{
by \\ Rūtenis Paulauskas ${ }^{1}$, Paulius Kamarauskas ${ }^{2}$, Ričardas Nekriošius ${ }^{3}$, \\ Nicholas Malcolm Bigwood ${ }^{4}$
}

The aim of this study was to investigate changes in physical and physiological responses to different modes of repeated sprint exercise by measuring speed, total time (sum of sprints), fatigue index, heart rate, local oxygen saturation, total haemoglobin content, and blood lactate. The volume of the physical load (distance, work and rest ratio) was the same in both exercises, but load specifics were different. The first mode consisted of $10 \times 30 \mathrm{~m}$ sprints (with one change of direction) interspersed with $30 \mathrm{~s}$ of passive recovery, while the second mode of $20 \times 15 \mathrm{~m}$ shuttle sprints interspersed with 15 s of passive recovery. Both exercise modalities were repeated three times with a five-minute rest interval between bouts with 7 days of recovery between each testing condition. Twelve highly trained male basketball players volunteered to participate in this study. Our study showed that different modes of repeated sprint exercises elicited a different physical response and metabolic demand. Longer sprints with directional changes placed a higher demand on the anaerobic glycolytic system compared to straight and more frequent sprint exercises. However, players' fatigue was more noticeable in shorter and more frequent sprints. Heart rate responses and local use of $\mathrm{O} 2$ showed a similar activity of aerobic reactions through the different exercises. During the sprints, players' SmO2 fell to $40 \%$ and recovered to the level of about $80 \%$ during passive rest intervals without showing differences in both modalities. This suggests that both types of sprint exercises can similarly stimulate aerobic metabolism.

Key words: local oxygen saturation, blood lactate, heart rate, speed, fatigue index.

\section{Introduction}

Basketball players cover about 4500 - 5000 $\mathrm{m}$ during a game (Taylor, 2003). Players sprint every $21 \mathrm{~s}$ on average and make about 100 high intensity actions of short duration (e.g. jumping or sprinting) for about $34 \%$ of the game time (Narazaki et al., 2009). In-game performance has been generally stated to be related to the volume (e.g. distance travelled) of work rather than intensity (e.g. pace) of work, with a resulting lack of emphasis on intense exercises in training.

Rodriguez-Alonso et al. (2003) examined physiological demands of competitive basketball, using blood lactate concentration (BLa) and sustained high heart rate (HR) response, showing that despite the relatively small fraction of game time spent in high-intensity activities, the physiological demands were remarkably high. This previous research allows us to simulate workout loads and choose the most appropriate assessment methods. Field tests with tasks including basketball-like movements (jumping, sprinting) are becoming more relevant. The ability to repeat multiple high-speed sprints plays a crucial role in basketball players' performance (Narazaki et al., 2009). Indeed, repeated sprint ability (RSA) is an important fitness component of

\footnotetext{
1 - Education Academy, Vytautas Magnus University, Vilnius, Lithuania.

2 - Faculty of Sport Biomedicine, Lithuanian Sports University, Kaunas, Lithuania.

3 - Faculty of Sport Biomedicine, Lithuanian Sports University, Kaunas, Lithuania.

4 - College of Medicine and Veterinary Medicine, Edinburgh Medical School, University of Edinburgh, Edinburgh, United Kingdom.
}

Authors submitted their contribution to the article to the editorial board.

Accepted for printing in the Journal of Human Kinetics vol. 72/2020 in April 2020. 
team-sport athletes performance (Spencer et al., 2005). To design a specific conditioning program, an understanding of important physiological mechanisms is crucial. RSA has been validated and identified as a reliable index of physical performance in basketball players (Castagna et al., 2007). The ability to maintain each sprint at high intensity without dramatic decrement can be a good predictor to differentiate between athletes of different levels (Gabbett, 2007). As RSA has become a validated capacity assessment tool, repeated sprint exercises remain an attractive basketball training strategy.

Due to the relatively short sprinting periods in basketball $\left(\begin{array}{lll}\leq 10 & \mathrm{~s}\end{array}\right)$, most energy contributing to RSA performance comes from the phosphocreatine (PCr) and the fast glycolysis systems (Turner and Stewart, 2013). In addition, research shows that the ability to resynthesize adenosine triphosphate and $\mathrm{PCr}$ during Repeated Sprint Exercises (RSE) may have a significant influence on RSA (Spencer et al., 2005). Hence, an individual with better aerobic fitness and a faster PCr-resynthesis rate during the recovery phase may perform better during RSE (Girard et al., 2011). Girard et al. (2011) showed a moderate correlation $(.62<\mathrm{r}<.68 ; \mathrm{p}<.05)$ between $\mathrm{VO} 2$ max and RSA performance (mean sprint time and sprint decrement). However, Castagna et al. (2007) showed no statistically significant relationship between aerobic capacity and RSA indices. Despite a number of previous studies, conclusions regarding aerobic demands of RSE are limited.

Near-infrared spectroscopy (NIRS) is a non-invasive method for measuring localised blood flow and oxygenation. The process is based on the differential proportion of wavelengths which are absorbed by oxygenated and deoxygenated $\mathrm{Hb}$ (De Blasi et al., 1993). The validity of the NIRS method has been demonstrated through its strong correlations with venous $\mathrm{O}_{2}$ saturation $\left(\mathrm{SmO}_{2}\right)$ at rest and during exercise $(r=0.92)$ (Mancini et al., 1994), and based on the reproducibility of its measurements during repeated incremental running $(r=0.87-0.88)$ and cycling ( $r=0.94-0.99)$ tests to exhaustion (Austin et al., 2005). $\mathrm{SmO}_{2}$ measurement inversely correlates with $\mathrm{VO}_{2}(\mathrm{r}=-0.7)$ during trail running on hilly terrain (Born et al., 2016). To our knowledge, no direct measurement of $\mathrm{SmO} 2$ in exercises of highly trained basketball players has been taken.
The aim of this study was to investigate changes in physical and physiological responses to different modes of RSE by measuring speed, total time (TT) (sum of sprints), fatigue index (FI), HR, $\mathrm{SmO}$, total haemoglobin content $(\mathrm{THb})$, and BLa.

\section{Methods}

\section{Participants}

Twelve highly trained male basketball players (age $21 \pm 1.9 \mathrm{y}$, body mass $86.2 \pm 5.8 \mathrm{~kg}$, body height $189.6 \pm 6.8 \mathrm{~cm}$, BMI $23.9 \pm 1.3 \mathrm{~kg} \cdot \mathrm{m}^{-2}$, standing reach $247.8 \pm 9.6 \mathrm{~cm}$ ) voluntarily participated in this study. All participants competed regularly at an elite level and had $12 \pm$ 1.9 years of basketball training experience with $\sim 10$ $\mathrm{h}$ of training per week. Prior to testing, all players were fit, free from injury and provided written informed consent to participate in the study. Tests were completed on a certified indoor wooden basketball flooring with players wearing basketball shoes and sportswear. To eliminate any influence of circadian rhythm, each participant completed all trials at the same time of the day (1 $3 \mathrm{pm}$ ) in ambient conditions of $20 \pm 0.5^{\circ} \mathrm{C}$ of temperature and $60 \pm 2 \%$ of relative humidity. Ethical approval conformed to the recommendations of the Declaration of Helsinki and was provided by the local Institutional Research Ethics Committee.

\section{Experimental procedure design}

We used a single-group repeatedmeasures study design in which the RSE mode was the independent variable, whereas speed, TT, FI, $\mathrm{SmO}_{2}, \mathrm{THb}, \mathrm{BLa}, \mathrm{HR}$ and FI between sets of exercise were dependent variables. Participants were familiarised with the RSE1 and RSE2 experimental procedure. The volume of work performed during both exercises was $900 \mathrm{~m}$ with the same exercise-to-rest ratio of 1:5, but with a different distribution of the exercise to rest ratio RSE1 being $6 \mathrm{~s}$ of sprint to $30 \mathrm{~s}$ of rest and RSE2 being $3 \mathrm{~s}$ of sprint to $15 \mathrm{~s}$ of rest. Participants performed two randomized exercise sessions with 7 days between each testing day in which all players completed three trials of maximal sprints with a 5 min rest interval between bouts. RSE1 consisted of ten $30 \mathrm{~m}$ shuttle sprints $(15 \mathrm{~m}+15 \mathrm{~m})$ with a change in direction of $180^{\circ}$, interspersed with $30 \mathrm{~s}$ of passive recovery (walking back to the starting line and waiting for the next sprint). Participants started from the starting line, sprinted 
in-line for $15 \mathrm{~m}$, touched a line on the floor with the outside foot and then ran back to the starting line as fast as possible. To eliminate discrepancies in fatigue between the participants' legs, they were asked to alternate the leg they started each sprint.

RSE2 consisted of twenty $15 \mathrm{~m}$ shuttle sprints interspersed with $15 \mathrm{~s}$ of passive recovery (walking back to the finish line and waiting for the next sprint). All exercise sessions started with a 10 min warm up of low-intensity running $(\sim 8 \mathrm{~km} \cdot \mathrm{h}$ $\left.{ }^{1}\right)$ and $5 \mathrm{~min}$ of standardised dynamic stretching.

The time for each single shuttle sprint was recorded using two sets of photocell gates (Brower Timing System, Salt Lake City, UT, USA; accuracy of $0.01 \mathrm{~s}$ ) placed at a height of $50 \mathrm{~cm}$ at the start and finish lines.

The FI was determined by taking the percentage difference between maximal and minimal speed performance during the RSE:

$$
\text { FI }(\%)=100-\frac{\text { SpeedMin } \times 100}{\text { SpeedMax }}
$$

All participants were asked to refrain from vigorous exercise 24 hours prior to testing. No additional strength, power, or plyometric training was performed during the testing period. Caffeine ingestion was forbidden before testing.

\section{Near-infrared spectroscopy}

NIRS measurements were made using the Moxy monitor (Moxy, Fortiori Design LLC, Minnesota, USA). The Moxy device is based on sequentially sending light waves $(630-850 \mathrm{~nm})$ from four light emitting diodes into the tissue beneath it and recording the amount of returned scattered light at two detectors positioned 12.5 and $25 \mathrm{~mm}$ from the light source. The penetration depth of the light received at each detector is half the distance between the light source and the detector. The scattered light is processed by an algorithm, which combines a tissue light propagation model and the Beer-Lambert law to determine the amount of light absorbed at wavelengths pertaining to oxygenated and deoxygenated $\mathrm{Hb}$. This allows calculation of $\mathrm{THb}$ present beneath the device, as well as the percentage of $\mathrm{Hb}$ containing $\mathrm{O}_{2}\left(\mathrm{SmO}_{2}\right)$. Because light passing into micro-vessels with a diameter greater than $1 \mathrm{~mm}$ is expected to be completely absorbed, it is assumed that the majority of reflected light comes from the capillaries, and thus the measurements obtained reflect the relative supply of $\mathrm{O}_{2}$ to the muscle versus its uptake (Fortiori Design LLC, 2015).

The Moxy was positioned on the participant's dominant leg, on the vastus lateralis, halfway between the greater trochanter and lateral epicondyle of the femur. Prior to placement, this area was trimmed with an electric razor (if necessary) and cleaned with alcohol swabs. The device was secured with a light shield and athletic tape to block ambient near-infra red light from interfering with the detectors, and its exact position was recorded and replicated for the second RSE session. After resting in a seated position for five minutes, measures for $\mathrm{SmO}_{2}$ and $\mathrm{THb}$ were recorded. Minimum local oxygen saturation $\left(\mathrm{SmO}_{2} \mathrm{~min}\right)$ was defined as the lowest value of $\mathrm{SmO}_{2} \mathrm{~min}$ registered during the sprints and average local oxygen saturation ( $\mathrm{SmO}_{2} \mathrm{avg}$ ) value was calculated during the sprints.

Blood Lactate Concentration Assessment

BLa concentration $\left(\mathrm{mmol} \cdot \mathrm{L}^{-1}\right)$, as a proxy for metabolic-anaerobic demand, was determined 3 minutes after the end of the RSE1 and RSE2 sessions (Hirvonen et al., 1987). Blood lactate samples were taken from the participants' fingertip and immediately analysed with a validated lactate analyser (Lactate Pro; Arkray, Tokyo, Japan).

\section{HR measures}

Participants were equipped with a telemetric HR monitor (Polar RS800 CX, Polar Electro $\mathrm{Oy}$, Finland). The HR was then continuously registered throughout the RSE and during the 5 min rest interval between trials. Raw HR data were automatically filtered using a moderate filter and all irregular heartbeats were replaced with interpolated adjacent R-R interval values using the Polar Software (Pro Trainer 5, Polar Electro, Finland). The maximum heart rate (HRmax) was defined as the highest value of the HR registered during the sprints and average heart rate (HRavg) value was calculated during the sprints.

\section{Statistical analysis}

Descriptive statistics were used to compute means and standard deviations (SD). Statistical analysis was performed with SPSS 23.0 (SPSS Inc. Chicago, IL, USA). The normal distribution of the variables was assessed for all groups under each condition using the ShapiroWilk test and visual inspection of Q-Q plots. Data 
were subsequently assessed using parametric statistics, with the maximum priority level being set at 0.05 . The homogeneity of variance was verified by the Bartlett's test. The analysis was performed using general a linear model for repeated measures analysis of variance (ANOVA) with a compound symmetry working covariance matrix on the following dependent variables: speed, TT, FI, SmO $2, \mathrm{HR}, \mathrm{THb}, \mathrm{FI}, \mathrm{BLa}$. The same model was used to analyse the effect of each work interval on the exercise mode among the RSE1 and RSE2. The level of significance was set at $p<0.05$.

\section{Results}

\section{Performance variables}

All performance variables for both RSE1 and RSE2 are shown in Table 1. A comparison of speed of RSE1 and RSE2 revealed a significant main effect on variables within different work modes $(\mathrm{F}=189.159, p<0.001)$. Repeated measures analysis within each work interval showed a significant decrease of speed in both (RSE1 and RSE2) exercises ( $\mathrm{F}=6.897, p<0.05$ and $\mathrm{F}=5.985, p$ $<0.05)$, respectively. The work mode revealed a significant effect on TT between RSE1 and RSE2 $(\mathrm{F}=176.732, p<0.001)$. During each bout, TT increased significantly (RSE1 F $=12.505, p<0.05$;
RSE2 $\mathrm{F}=5.785, p<0.05)$. The study showed that the FI changed significantly $(\mathrm{F}=18.012 ; p<0.01)$ within RSE1 and RSE2.

\section{Physiological variables}

Fluctuations in $\mathrm{HR}$ and $\mathrm{SmO}_{2}$ variables during the exercise and rest periods are shown in Figures 1 and 2. As RSE1 and RSE2 exercise intensity increased, there was an increase in the HR and a decline in $\mathrm{SmO}_{2}$. Data detailing physiological variables are presented in Table 2. Our study showed that during each work interval the HRmax increased significantly (RSE1 $\mathrm{F}=6.017, p<0.05$; RSE2 $\mathrm{F}=17.959, p<0.05)$, but with no significant difference between RSE1 and RSE2. The HRavg in both RSE1 and RSE2 increased significantly (RSE1 $\mathrm{F}=16.817, p<0.001$; RSE2 $\mathrm{F}=63.910, p<0.001$ ), but with no significant difference between the two modes of exercise $(F=0.013, p>0.05)$. No significant differences were found in $\mathrm{SmO}_{2 \mathrm{~min}}$ within work intervals and between RSE1 and RSE2 $(\mathrm{F}=0.276, p>0.05)$. There was also no significant difference in $\mathrm{SmO}_{2 \text { avg }}$ within work intervals and between RSE1 and RSE2 ( $\mathrm{F}=0.113, p>0.05)$. THb showed little variation throughout each test and was not significantly associated with changes in exercise mode $(F=0.426, p>0.05)$.

Table 1

Results of physical variables analysed during different mode of repeated sprint exercises (RSE1 and RSE2)

\begin{tabular}{|c|c|c|c|c|c|c|c|c|c|}
\hline \multirow[b]{2}{*}{ Variables } & \multicolumn{4}{|c|}{ RSE1 } & \multicolumn{4}{|c|}{ RSE2 } & \multirow{2}{*}{$\begin{array}{c}\text { RSE1- } \\
\text { RSE2 } \\
\text { F }\end{array}$} \\
\hline & 1 bout & 2 bout & 3 bout & $\mathrm{F}$ & 1 bout & 2 bout & 3 bout & $\mathrm{F}$ & \\
\hline Speed $\left(\mathrm{m} \cdot \mathrm{s}^{-1}\right)$ & $\begin{array}{c}5.14 \pm \\
0.14\end{array}$ & $\begin{array}{c}5.07 \pm \\
0.17\end{array}$ & $\begin{array}{c}5.01 \pm \\
0.20\end{array}$ & $6.897^{*}$ & $\begin{array}{c}5.63 \pm \\
0.17\end{array}$ & $\begin{array}{c}5.61 \\
\pm 0.15\end{array}$ & $\begin{array}{c}5.56 \pm \\
0.17\end{array}$ & $\begin{array}{l}5.985 \\
*\end{array}$ & $\begin{array}{c}189.159 \\
*\end{array}$ \\
\hline TT (s) & $\begin{array}{c}58.45 \pm \\
1.63\end{array}$ & $\begin{array}{c}59.25 \pm \\
2.03\end{array}$ & $\begin{array}{c}60.02 \pm \\
2.41\end{array}$ & $12.505^{*}$ & $\begin{array}{c}53.37 \pm \\
1.64\end{array}$ & $\begin{array}{c}53.58 \pm \\
1.45\end{array}$ & $\begin{array}{c}54.04 \pm \\
1.63\end{array}$ & $\begin{array}{l}5.785 \\
*\end{array}$ & $\begin{array}{c}176.732 \\
*\end{array}$ \\
\hline FI (\%) & $\begin{array}{c}6.14 \pm \\
2.80\end{array}$ & $\begin{array}{c}7.59 \pm \\
2.67\end{array}$ & $\begin{array}{c}7.09 \pm \\
3.45\end{array}$ & 1.222 & $\begin{array}{c}10.92 \pm \\
3.86\end{array}$ & $\begin{array}{c}11.58 \pm \\
2.65\end{array}$ & $\begin{array}{c}10.75 \pm \\
3.12\end{array}$ & 0.368 & $\begin{array}{c}18.012 \\
*\end{array}$ \\
\hline
\end{tabular}

Notes: The value expressed as mean and standard deviation (SD) in both repeated sprint exercises (RSE1) and (RSE2). *Significant differences $(p<0.05)$. 


\section{Table 2}

Results of physiological variables analysed during different mode of repeated sprint exercises (RSE1 and RSE2)

\begin{tabular}{|c|c|c|c|c|c|c|c|c|c|}
\hline \multirow[b]{2}{*}{ Variables } & \multicolumn{4}{|c|}{ RSE1 } & \multicolumn{4}{|c|}{ RSE2 } & \multirow{2}{*}{$\begin{array}{c}\text { RSE1- } \\
\text { RSE2 } \\
\text { F }\end{array}$} \\
\hline & 1 bout & 2 bout & 3 bout & F & 1 bout & 2 bout & 3 bout & F & \\
\hline $\begin{array}{c}\mathrm{SmO}_{2} \min \\
(\%)\end{array}$ & $\begin{array}{c}25.66 \pm \\
12.44\end{array}$ & $\begin{array}{c}19.66 \pm \\
13.03\end{array}$ & $\begin{array}{c}20.83 \pm \\
16.19\end{array}$ & 3.230 & $\begin{array}{c}26.08 \pm \\
22.48\end{array}$ & $\begin{array}{c}23.91 \pm \\
22.87\end{array}$ & $\begin{array}{c}22.00 \pm \\
23.91\end{array}$ & 0.601 & 0.276 \\
\hline $\begin{array}{c}\mathrm{SmO}_{2} \text { avg } \\
(\%)\end{array}$ & $\begin{array}{c}40.83 \pm \\
12.95\end{array}$ & $\begin{array}{c}37.77 \pm \\
13.07\end{array}$ & $\begin{array}{c}40.30 \pm \\
15.71\end{array}$ & 0.981 & $\begin{array}{c}37.01 \pm \\
21.83\end{array}$ & $\begin{array}{c}36.33 \pm \\
21.42\end{array}$ & $\begin{array}{c}40.16 \pm \\
21.67\end{array}$ & 1.466 & 0.113 \\
\hline $\mathrm{THb}\left(\mathrm{dL}^{-1}\right)$ & $\begin{array}{c}12.36 \pm \\
0.52\end{array}$ & $\begin{array}{c}12.43 \pm \\
0.52\end{array}$ & $\begin{array}{c}12.36 \pm \\
0.49\end{array}$ & 1.191 & $\begin{array}{c}12.41 \pm \\
0.59\end{array}$ & $\begin{array}{c}12.39 \pm \\
0.59\end{array}$ & $\begin{array}{c}12.33 \pm \\
0.60\end{array}$ & 1.611 & 0.426 \\
\hline $\begin{array}{l}\mathrm{HR}_{\max } \\
(\mathrm{bpm})\end{array}$ & $\begin{array}{l}174.58 \\
\pm 7.61\end{array}$ & $\begin{array}{l}178.25 \\
\pm 5.48\end{array}$ & $\begin{array}{c}181.83 \pm \\
10.17\end{array}$ & $\begin{array}{l}6.017 \\
*\end{array}$ & $\begin{array}{c}174.08 \pm \\
8.77\end{array}$ & $\begin{array}{c}177.75 \pm \\
8.51\end{array}$ & $\begin{array}{c}179.33 \pm \\
7.35\end{array}$ & $\begin{array}{c}17.959 \\
*\end{array}$ & 0.819 \\
\hline HRavg (bpm) & $\begin{array}{l}162.80 \\
\pm 9.14\end{array}$ & $\begin{array}{l}169.06 \\
\pm 6.65\end{array}$ & $\begin{array}{c}169.46 \pm \\
6.54\end{array}$ & $\begin{array}{c}16.817 \\
*\end{array}$ & $\begin{array}{c}161.32 \pm \\
9.69\end{array}$ & $\begin{array}{c}169.67 \pm \\
8.95\end{array}$ & $\begin{array}{c}170.84 \pm \\
8.18\end{array}$ & $\begin{array}{c}63.910 \\
*\end{array}$ & 0.013 \\
\hline $\begin{array}{l}\text { BLa } \\
\left(\mathrm{mmol} \cdot \mathrm{L}^{-1}\right)\end{array}$ & - & - & $\begin{array}{c}13.02 \pm \\
2.28\end{array}$ & - & - & - & $\begin{array}{c}8.53 \pm \\
3.44\end{array}$ & - & $\begin{array}{c}34.070 \\
*\end{array}$ \\
\hline
\end{tabular}

Notes: The value expressed as mean and standard deviation (SD) in both repeated sprint exercises (RSE1) and (RSE2). *Significant differences $(p<0.05)$

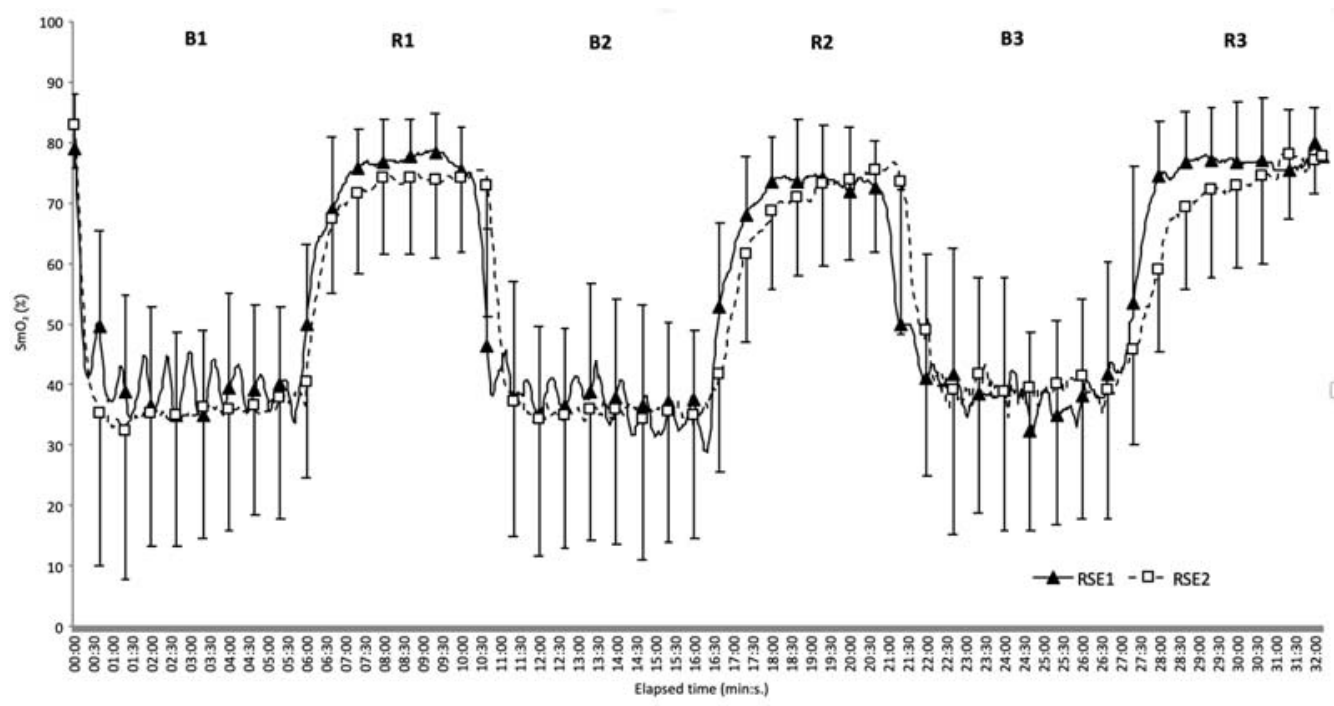

Figure 1

Representative local oxygenation ( $\mathrm{SmO} 2)$ data during repeated sprint exercises.

The open cube and closed triangle indicate RSE1 and RSE2 values in every 20-s window, respectively. The $B$ and $R$ denote active bouts and resting periods, respectively 


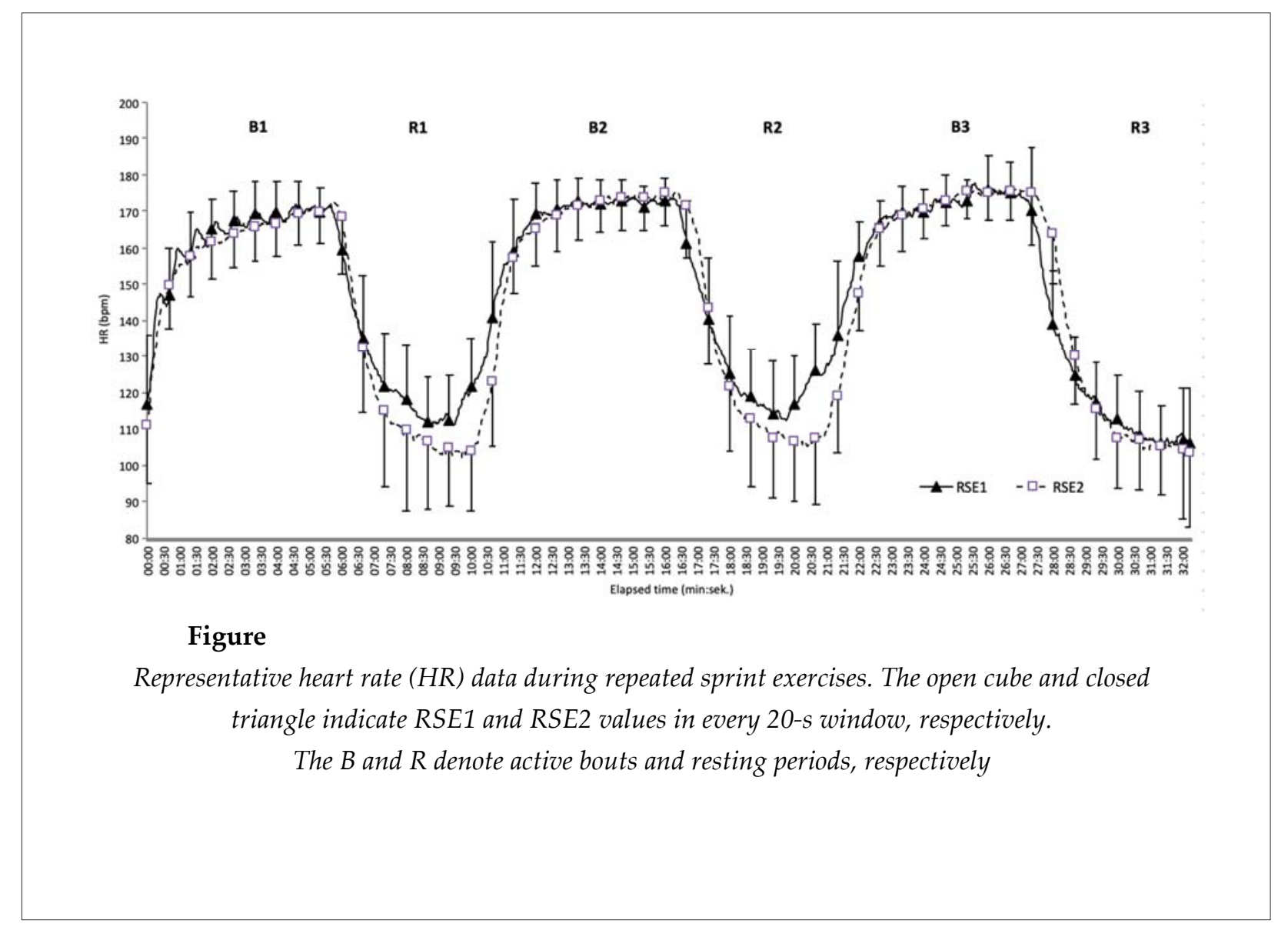

\section{Discussion}

The first goal of this study was to assess performance differences in RSE1 (one change of direction during the sprint) with respect to RSE2 (straight sprints). The speed achieved during both exercise modes significantly decreased with subsequent sprints. The RSE1 average sprint speed was by $8.7-9.9 \%$ lower than RSE2. The TT difference between exercises varied from 5.08 to $5.98 \mathrm{~s}$ on average.

Given these differences, it could be suggested that RSE1 and RSE2 utilise different aspects of motor function. Brughelli et al. (2008) highlighted that straight sprints (in-line) and changes of direction had mostly separate motor qualities because the shared variance was $\leq 53 \%$. Examining findings reported by Brughelli et al. (2008), most correlations between change of direction and straight running speed would be described as moderate $(r=0.3-0.5)$. Changes of direction played a key role, and it was considered as the interplay of a number of physical and neuromuscular components (Sheppard and
Young, 2006).

The fatigue results show that a significant interaction exists between each exercise mode. The FI during both exercises did not significantly decrease. In shorter sprints of RSE2, recovery time between sprints was also shorter. However, the FI of RSE2 was $3.6-4.8 \%$ higher than of RSA1. This overall finding supports previous research reporting that performance and fatigue during repeated sprints are strongly influenced by the recovery duration (Attene et al., 2014). Glaister (2005) claims that fatigue can often be masked by a potentiation effect. This effect is apparent in a number of investigations, the mechanisms of which remain largely unresolved (Hamilton et al., 1991; MacIntosh et al., 2002).

Our research into the physiological demands of RSE indicates that these workouts place considerable demand on both aerobic and anaerobic pathways. The average physiological response to repeated sprint work is reported to be within intensities of $37-40 \%$ maximum $\mathrm{SmO}_{2 a v g}$ and HRmean of $92-95 \%$ of maximum. Different modes of RSE did not show significant difference 
in the aerobic muscle metabolism. Meanwhile, the BLa content after RSE1 was $13.02 \mathrm{mmol} \cdot \mathrm{L}^{-1}$, and after RSE2 significantly lower at $8.53 \mathrm{mmol} \cdot \mathrm{L}^{-1}$, which shows active anaerobic metabolism. Hamilton et al. (1991) found strong correlations between peak blood lactate and peak speed $(\mathrm{r}=$ $0.90, p<0.01$ ) and between peak blood lactate and peak power fatigue $(\mathrm{r}=0.92, p<0.01)$ during $10 \times$ 6-s all-out sprints with $30 \mathrm{~s}$ recovery periods implying a high glycolytic rate during this activity which has been confirmed by the high lactate concentration observed in another study using similar protocols (Hamilton et al., 1991).

The indication that performance during repeated sprints is regulated predominantly by $\mathrm{PCr}$ availability provides the most likely explanation for the significant differences between the two exercise modes in terms of BLa accumulation. Indeed, higher RSE1 BLa may be associated with lower $\mathrm{PCr}$ during the exercise protocol with longer sprints and one change of direction, as accumulation of metabolites in the process of ATP-Cr splitting (i.e., pyruvate, adenosine diphosphate, and adenosine monophosphate) is suggested to be a stimulus for anaerobic glycolysis (Crowther et al., 2002). However, previous investigation on the physiological response to RSA have reported an evident inhibition of glycolysis over multiple sprints (Glaister et al., 2008). It should be noted that BLa concentration is only a reflection of the dynamic balance between its production and clearance, and only one measurement at the third minute after the end of the test may not truly reflect the BLa level given its normal variability (Glaister et al., 2008).

Recordings of muscle oxygenation during RSE1 and RSE2 are presented in Figure 1. A decrease in muscle oxygenation during exercise would reflect an increase in the degree of muscle oxygen diffusion as well as muscle oxygenation would reflect the balance between muscle oxygen utilization and supply (Shibuya and Tanaka, 2003). Our study showed that the different modes of workouts did not have a significant effect on muscle oxygenation. The moderate inverse correlation between $\mathrm{SmO}_{2}$ and $\mathrm{VO}_{2}(\mathrm{r}=-0.73)$ is in accordance with Born et al. (2016) who found that changes in $\mathrm{SmO}_{2}$ in the vastus lateralis of elite runners competing in an undulating trail running race closely corresponded to changes in $\mathrm{VO}_{2}$.
Shibuya and Tanaka (2003) concluded that one of the limiting factors of $\mathrm{VO}_{2 \max }$ was the muscle oxygen diffusion capacity, and $\mathrm{SmO}_{2}$ during exercise could be one of the indexes of muscle oxygen diffusion capacity. Since $\mathrm{SmO}_{2}$ is a measure of the mean localised muscle capillary content, greater $\mathrm{O}_{2}$ muscle uptake means the $\mathrm{O}_{2}$ content of the capillaries perfusing the muscle will decrease, as this includes the inflow of $\mathrm{O}_{2}$ as well as the outflow of $\mathrm{CO}_{2}$ (Bhambhani, 2004). In addition, the greater rate of mechanical work requiring greater $\mathrm{VO}_{2}$ results in an increased concentration of intramuscular adenine diphosphate, which signals a need for more oxidative ATP production and further promotes $\mathrm{O}_{2}$ diffusion into the muscle (Bassett and Howley, 2000).

Very small variation was found in $\mathrm{THb}$ values throughout exercises, despite significant changes in all other measured variables. It is likely that our participants had a sufficient supply of oxygenated $\mathrm{Hb}$ to the muscles throughout the test, and were not limited by a lack of $\mathrm{O}_{2}$ availability, even at the maximum intensities.

The HR significantly increased during both RSE modes. Dynamics of the HR during particular exercises is presented in Figure 2. After repeated sprints, the blunted responsiveness of the HR could be related to a higher anaerobic contribution during exercise and the elevation of adrenergic factors and local metabolites during recovery (Buchheit et al., 2007). Along this line of reasoning, those individuals showing distinct aerobic and anaerobic contributions to a given exercise load would therefore also display disparate post-exercise HR responses (Del Roso et al., 2017). Daanen at al. (2012) claim that HR discriminates between the mode and intensities of exercise. Our study cannot confirm this statement because there was no significant difference in HR dynamics between the different modes of sprint exercises. HR recovery in healthy individuals is governed by the autonomic nervous system and it is characterised by parasympathetic reactivation and sympathetic withdrawal (Borresen and Lambert, 2008; Daanen et al., 2012). It was also argued that as the autonomic nervous system interacts with other physiological systems, monitoring of the HR recovery as a reflection of the autonomic nervous system in response to an exercise stimulus may reflect body's ability to respond to the stress of such a stimulus (Borresen 
and Lambert, 2007). Our study of HR response of recovery kinetics in basketball players after different modes of exercise does not support this allegation.

\section{Conclusion}

In conclusion we may state that different modes of repeated sprint exercises cause a different physical response and metabolic demands in highly trained basketball players. Longer sprints with directional changes place a higher demand on the anaerobic glycolytic system compared to straight and more frequent sprint exercises. However, basketball player's fatigue is more noticeable in shorter and more frequent sprints. The mechanisms of fatigue and the factors that regulate the same require further investigation. $\mathrm{HR}$ responses and local use of $\mathrm{O}_{2}$ show a similar activity of aerobic reactions through both types of exercise. During the sprints basketball players' $\mathrm{SmO}_{2}$ falls to $40 \%$ and recovers to the level of about $80 \%$ during the passive recovery periods without showing significant differences between exercises. This proves that both workouts can similarly stimulate aerobic metabolism. Therefore, the concept of the distance covered during the match or exercise, the rest interval and the work ratio, becomes incomplete in describing physical activity because the specificity of physical activity can lead to different physiological responses. A greater understanding of the physiological response to repeated sprint exercises is likely to help athletes and coaches improve basketball performance.

\section{References}

Attene G, Pizzolato F, Calcagno G, Ibba G, Pinna M, Salernitano G, Padulo J. Sprint vs. intermittent training in young female basketball players. J Sport Med Phys Fit, 2014; 54(2): 154-161

Austin KG, Daigle KA, Patterson P, Cowman J, Chelland S, Haymes EM. Reliability of near-infrared spectroscopy for determining muscle oxygen saturation during exercise. Res Q Exercise Sport, 2005; 76: 440-449. doi:10.1080/02701367.2005.10599317

Bassett DR, Howley ET. Limiting factors for maximum oxygen uptake and determinants of endurance performance. Med Sci Sport Exer, 2000; 32: 70- 84. doi:10.1097/00005768-200001000-00012

Bhambhani YN. Muscle oxygenation trends during dynamic exercise measured by near infrared spectroscopy. Can J Appl Physiol, 2004; 29: 504-523. doi:10. 1139/h04-033

Born D, Stöggl T, Swarén M, Björklund G. Running in hilly terrain: NIRS is more accurate to monitor intensity than heart rate. Int J Sports Physiol Perform, Advance online publication, 2016. doi:10.1123/ijspp.2016-0101

Borresen J, Lambert MI. Autonomic control of heart rate during and after exercise: Measurements and implications for monitoring training status. Sports Med, 2008; 38(8): 633-646. doi:10.2165/ 00007256200838080-00002

Borresen J, Lambert MI. Changes in heart rate recovery in response to acute changes in training load. Eur J Appl Physiol, 2007; 101(4): 503-511. doi:10.1007/s00421-007-0516-6

Brughelli M, Cronin J, Levin G, Chaouachi A. Understanding change of direction ability in sport: A review of resistance training studies. Sports Med, 2008; 38: 1045-1063

Buchheit M, Laursen PB, Ahmaidi S. Parasympathetic reactivation after repeated sprint exercise. Am J PhysiolHeart C, 2007; 293(1): 133-141. doi:10.1152/ajpheart.00062.2007

Castagna C, Manzi V, D'Ottavio S, Annino G, Padua E, Bishop D. Relation between maximal aerobic power and the ability to repeat sprints in young basketball players. J Strength Cond Res, 2007; 21: 1172-1176

Crowther GJ, Carey MF, Kemper WF, Conley KE. Control of glycolysis in contracting skeletal muscle. I. Turning it on. Am J Physiol-Endoc M, 2002; 282(1): 67-73

Daanen HA, Lamberts RP, Kallen VL, Jin A, Van Meeteren NL. A systematic review on heart-rate recovery to monitor changes in training status in athletes. Int J Sports Physiol Perform, 2012; 7(3): 251-260

De Blasi RA, Cope M, Elwell C, Safoue F, Ferrari M. Noninvasive measurement of human forearm oxygen consumption by near infrared spectroscopy. Eur J Appl Physiol O, 1993; 67: 20-25. doi:10.1007/BF00377698 
Del Rosso S, Nakamura FY, Boullosa DA. Heart rate recovery after aerobic and anaerobic tests: is there an influence of anaerobic speed reserve? J Sport Sci, 2017; 35(9): 820-827. doi:10.1080/02640414.2016.1166391

Fortiori Design LLC. Introduction to muscle oxygen monitoring with Moxy; 2015 Available at: http://cdn2.hubspot.net/hub/188620/file-433442739-pdf/docs/moxy-ebook-intro-to-muscleoxygen.pdf?t=1488816603832; Accessed on 05.03.2018

Gabbett TJ. Physiological and anthropometric characteristics of elite women rugby league players. J Strength Cond Res, 2007; 21(3): 875-881. PubMed doi:10.1519/R-20466.1

Girard O, Mendez-Villanueva A, Bishop D. Repeated-sprint ability - part I: factors contributing to fatigue. Sports Med, 2011; 41 (8): 673-694. doi:10.2165/11590550-000000000-00000

Glaister M. Multiple sprint work: physiological responses, mechanisms of fatigue and the influence of aerobic fitness. Sports Med, 2005; 35(9): 757-777. PubMed doi:10.2165/00007256-200535090-00003

Glaister M, Howatson G, Pattison JR, McInnes G. The reliability and validity of fatigue measures during multiple-sprint work: An issue revisited. J Strength Cond Res, 2008; 22(5): 1597-1601

Hamilton AL, Nevill ME, Brooks S, Williams C. Physiological responses to maximal intermittent exercise: Differences between endurance-trained runners and games players. J Sport Sci, 1991; 9(4): 371-382. doi:10.1080/02640419108729897

Hirvonen J, Rehunen S, Rusko H, Harkonen M. Breakdown of high- energy phosphate compounds and lactate accumulation during short supramaximal exercise. Eur J Appl Physiol O, 1987; 56(3): 253-259

MacIntosh BR, Rassier DE. What is fatigue? Can J Appl Physiol, 2002; 27(1): 42-55

Mancini DM, Bolinger L, Li H, Kendrick K, Chance B, Wilson JR. Validation of near-infrared spectroscopy in humans. J Appl Physiol, 1994; 77: 2740-2747. PMID: 7896615

Narazaki K, Berg K, Stergiou N, Chen B. Physiological demands of competitive basketball. Scand J Med Sci Spor, 2009; 19: 425-432

Rodriguez-Alonso M, Fernandez-Garcia B, Perez-Landaluce J, Terrados N. Blood lactate and heart rate during national and international women's basketball. J Sport Med Phys Fit, 2003; 43(4): 432-436

Sheppard JM, Young WB. Agility literature review: Classifications, training and testing. J Sport Sci, 2006; 24: 919-932

Shibuya K, Tanaka J. Skeletal Muscle Oxygenation During Incremental Exercise Archives of Physiology and Biochemistry. J Metab Dis, 2003; 111(5): 475-478

Spencer M, Bishop D, Dawson B, Goodman C. Physiological and metabolic responses of repeated-sprint activities: specific to field-based team sports. Sports Med, 2005; 35(12): 1025-1044. PubMed doi:10.2165/00007256- 200535120-00003

Taylor J. Basketball: applying time motion data to conditioning. J Strength Cond Res, 2003; 25: 57-64

Turner AN, Stewart PF. Repeat sprint ability. J Strength Cond Res, 2013; 35(1): 37-41. doi:10.1519/SSC.0b013e3182824ea4

\section{Corresponding author:}

\section{Prof. dr. Rūtenis Paulauskas}

Vytautas Magnus University, Education Academy.

T. Ševčenkos g. 31, 03111 Vilnius, tel. (8 5) 27902 81, Lithuania.

Phone number: +37069839079

E-mail: rutenis.paulauskas@vdu.lt 